\title{
Unveiling Potent Photooxidation Behavior of Catalytic Photoreductants
}

\author{
Karina Targos,,${ }^{\ddagger}$ Oliver P. Williams, $\stackrel{\ddagger}{\ddagger}$ and Zachary K. Wickens* \\ Department of Chemistry, University of Wisconsin-Madison, Madison, Wisconsin 53706, United States.
}

Supporting Information Placeholder

\begin{abstract}
We describe a photocatalytic system that reveals latent photooxidant behavior from one of the most reducing conventional photoredox catalysts, $\mathrm{N}$ phenylphenothiazine (PTH). This aerobic photochemical reaction engages difficult to oxidize feedstocks, such as benzene, in $\mathrm{C}\left(\mathrm{sp}^{2}\right)-\mathrm{N}$ coupling reactions through direct oxidation. Mechanistic studies are consistent with activation of PTH via photooxidation and that Lewis acid co-catalysts scavenge inhibitors formed upon catalyst activation.
\end{abstract}

Reactions driven by single electron transfer (SET) are pervasive in organic chemistry. Consequently, new strategies to induce redox events are poised to profoundly impact synthetic chemistry. ${ }^{1}$ Photoredox catalysis has unlocked a broad range of attractive new transformations through conversion of energy from readily accessible LEDs into chemical redox potential. ${ }^{2}$ However, only a portion of this energy ${ }^{3}$ can be harnessed due to inevitable energy losses from vibrational relaxation, internal conversion, and intersystem crossing. ${ }^{4}$ Despite tremendous effort in photoredox catalyst design, ${ }^{4,5}$ excited state potentials beyond roughly -2 and $+2 \mathrm{~V} v s$ SCE remain difficult to achieve using conventional photocatalysis (Figure 1A). ${ }^{6}$ Unfortunately, this redox window excludes numerous abundant hydrocarbon feedstocks from facile photoinduced electron transfer. ${ }^{7}$

To overcome the energetic limitations intrinsic to conventional photoredox catalysis, König and coworkers recently designed a photocatalytic system that drives challenging reductive SET events using the energy of two photons rather than one. This consecutive photoninduced electron transfer $(\text { conPET })^{8}$ strategy relies on a catalytic photooxidant and sacrificial reductant that, upon irradiation, result in a potent radical anion photoreductant (Figure 1B). Despite its mechanistic complexity, this approach is practical and operationally simple; it leverages inexpensive and safe LEDs to accomplish reactions that otherwise require UV photoreactors or harsh chemical reductants. Following proof-of-concept aryl halide

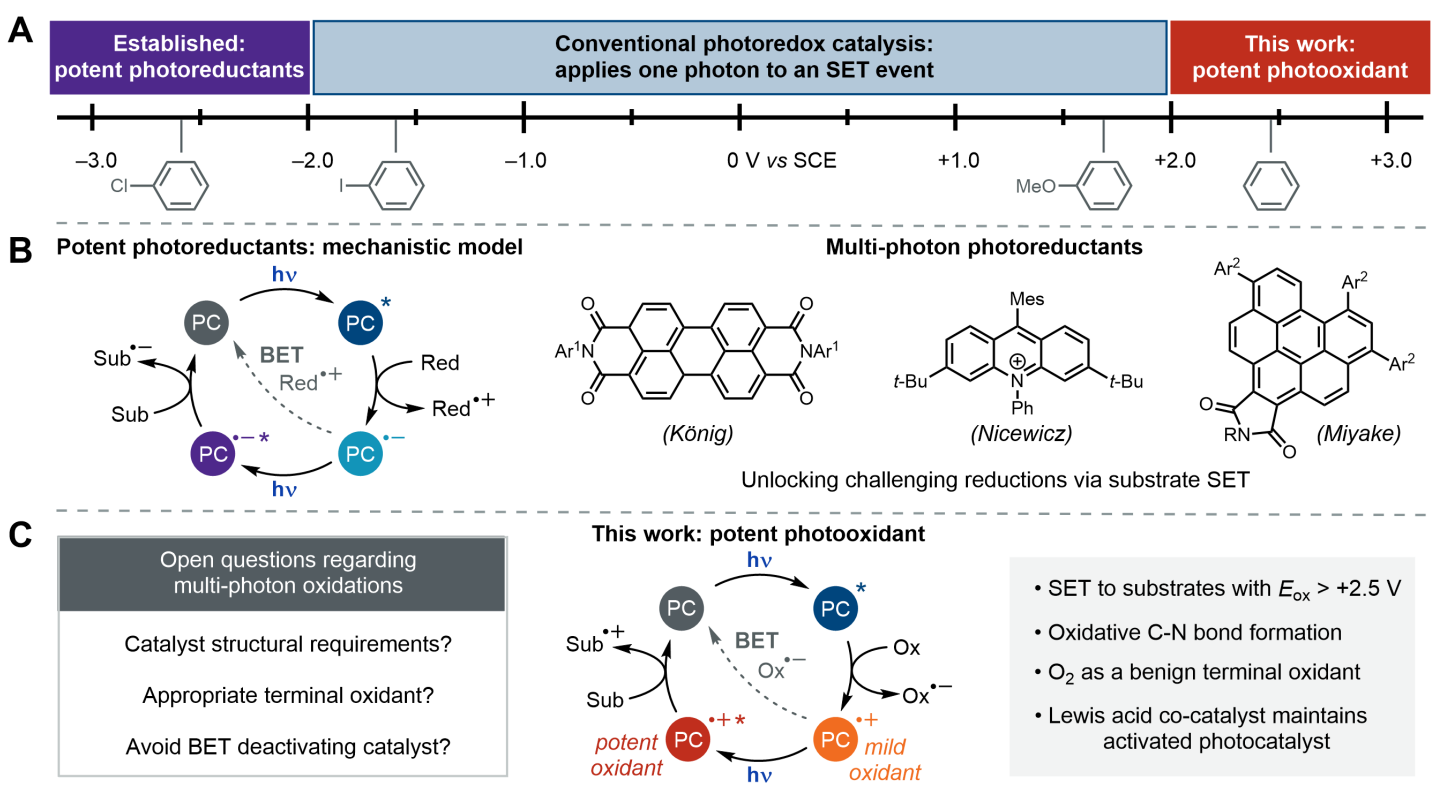

Figure 1. (A) Overview of redox potentials in photoredox catalysis. (B) Overview of multi-photon photoreductants. Full catalyst structures available in SI. (C) Overview of research described herein. 
reductions, ${ }^{8,9}$ this approach has enabled photochemical alternatives to alkali metal reductants in reactions such as Birch reductions ${ }^{10}$ and sulfonamide cleavage. ${ }^{11}$

In contrast to the progress in photoreductions, oxidations driven by the consumption of multiple photons have remained elusive. We suspect that this is the consequence of two inextricable challenges: (1) the catalyst must be a competent photocatalyst in both the closed shell and radical cation states $^{2 a, 8 b}$ and (2) the terminal oxidant must efficiently activate the catalyst but not otherwise interfere with the reaction (Figure 1C). ${ }^{12}$ Given the difficulty applying multiple photons towards a challenging SET oxidation, photoredox reactions initiated by SET oxidation are typically limited to electron-rich hydrocarbon substrates. ${ }^{13}$

Our group is investigating diverse strategies to expand the redox potentials accessible via photoredox catalysis. ${ }^{14}$ We questioned whether conventional photoreductants, which typically possess persistent radical cation states, could be repurposed as strong photooxidants using a conPET strategy. ${ }^{15}$ We hypothesized photochemical conditions designed to drive these photocatalysts towards their oxidized congeners could reveal oxidation behavior. To probe this hypothesis, we targeted cyclic triarylamine photoreductants. These are a well-established and modular family of neutral photoreductants ${ }^{6 \mathrm{~d}, 16}$ and isolated reports suggest their radical cation congeners could exhibit photochemical activity. ${ }^{17}$ We selected the Nicewicz-type ${ }^{13 e}$ oxidative coupling of arenes and $\mathrm{N}$-heterocyclic nucleophiles as a model reaction. This synthetically valuable transformation is representative of the general challenges in oxidative photoredox catalysis; it has been predominantly limited to electron-rich arene substrates, such as anisole derivatives. ${ }^{18}$ Difficult to oxidize arene substrates, such as benzene, mandate high energy UV light (UVB or shorter), ${ }^{6 a}$ strong ground state oxidants (e.g. DDQ that absorb visible light, ${ }^{19}$ or more technically complex electrophotocatalytic approaches. ${ }^{20,21}$ Thus, beyond providing a proof-of-concept, we envisioned that promoting this transformation using a stable photocatalyst with only inexpensive LEDs would be a synthetically useful complement to existing methods.

First, we examined three distinct photoreductants ${ }^{6 \mathrm{~d}, 22}$ and a range of oxidants for activity in the oxidative coupling of benzene $\left(E_{\text {ox }}=2.5 \mathrm{~V} v \text { s. SCE }\right)^{23}$ and pyrazole 1 (Table $1)$. We initially aimed to generate the catalyst radical cation congener via photoreduction of reagents that undergo irreversible decomposition after SET to avoid catalyst deactivation via back electron transfer (BET). Excitingly, these data revealed that $\mathrm{N}$-phenylphenothiazine (PTH), the most reducing photocatalyst of the series, could promote this challenging oxidative coupling in low yield using organohalides as the oxidant. A sufficiently strong oxidant to oxidize each catalyst to the corresponding
Table 1. Survey of oxidants and photoreductants. ${ }^{a-d}$

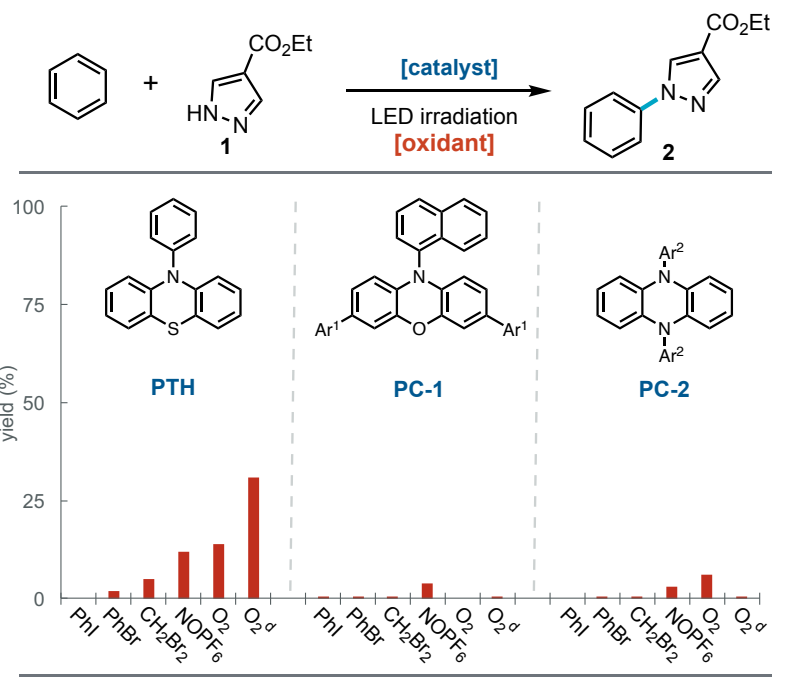

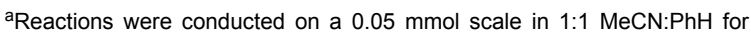
$24 \mathrm{~h}$, unless noted otherwise, using 2 equiv oxidant or $1 \mathrm{~atm} \mathrm{O}_{2} . \mathrm{Ar}^{1}=4$ -

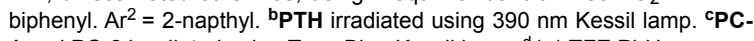

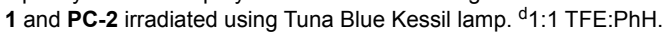

radical cation without additional energy from light, $\mathrm{NOPF}_{6}{ }^{24}$ provided low yield of benzene oxidation products using all three catalysts. However, under one atmosphere of $\mathrm{O}_{2}$, PTH promoted oxidative coupling in promising yield (14\%). Given the enhanced stability of radical cations in fluorinated alcohol solvents, ${ }^{25}$ we substituted $\mathrm{MeCN}$ for trifluoroethanol (TFE). This resulted in a modest increase in reaction yield with PTH but only traces of product with the other two catalysts. Of note, while most photoredox catalysts undergo rapid intersystem crossing to a long-lived triplet, ${ }^{2 a, 5 c}$ PTH is a singlet excited state reductant. ${ }^{26}$ This property circumvents photocatalyst deactivation by triplet-triplet annihilation with $\mathrm{O}_{2}$.

We suspected that BET between PTH radical cation and superoxide $^{27}$ might attenuate reactivity under these conditions (Figure 2). ${ }^{28}$ Indeed, when synthetically prepared PTH radical cation is treated with $\mathrm{KO}_{2}$, we observe a rapid color change and reformation of PTH by ${ }^{1} \mathrm{H}-\mathrm{NMR}$. Given that superoxide generation is inextricable from aerobic

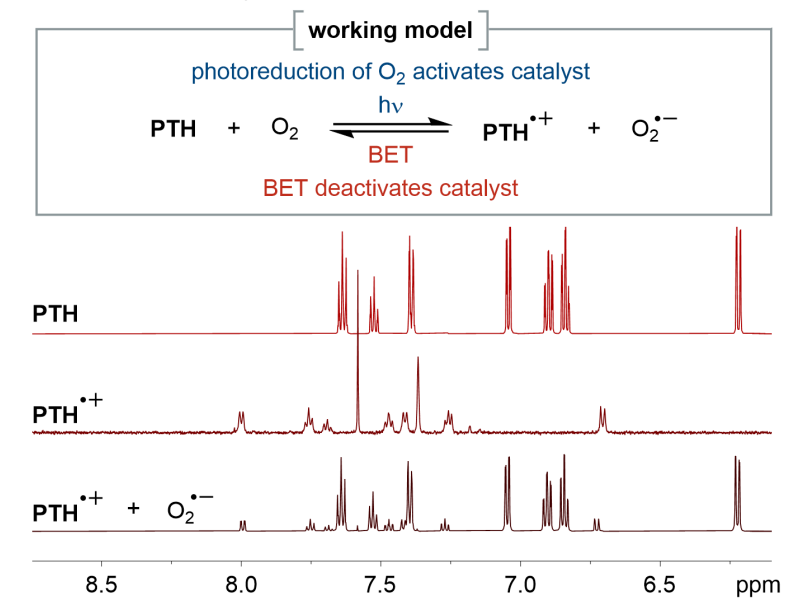

Figure 2. ${ }^{1} \mathrm{H}$ NMR spectroscopic evidence supporting working model for catalyst deactivation pathways. 
catalyst activation, this observation could account for the modest reactivity of this catalytic system (Table 2, entry 1 ). As expected, addition of $5 \mathrm{~mol} \% \mathrm{KO}_{2}$ to the reaction mixture completely suppressed product formation (entry 2). We hypothesized that additives capable of sequestering or scavenging this inhibitor would enhance the observed reactivity. Guided by this model, we found addition of one equivalent of an inexpensive, redox innocent Lewis acid, $\mathrm{LiClO}_{4}$, dramatically improved the yield of oxidative coupling product (entry 3). Reduction of the $\mathrm{LiClO}_{4}$ loading to a substoichiometric quantity $(20 \mathrm{~mol} \%)$ retained the benefits Table 2. Reaction optimization ${ }^{a}$

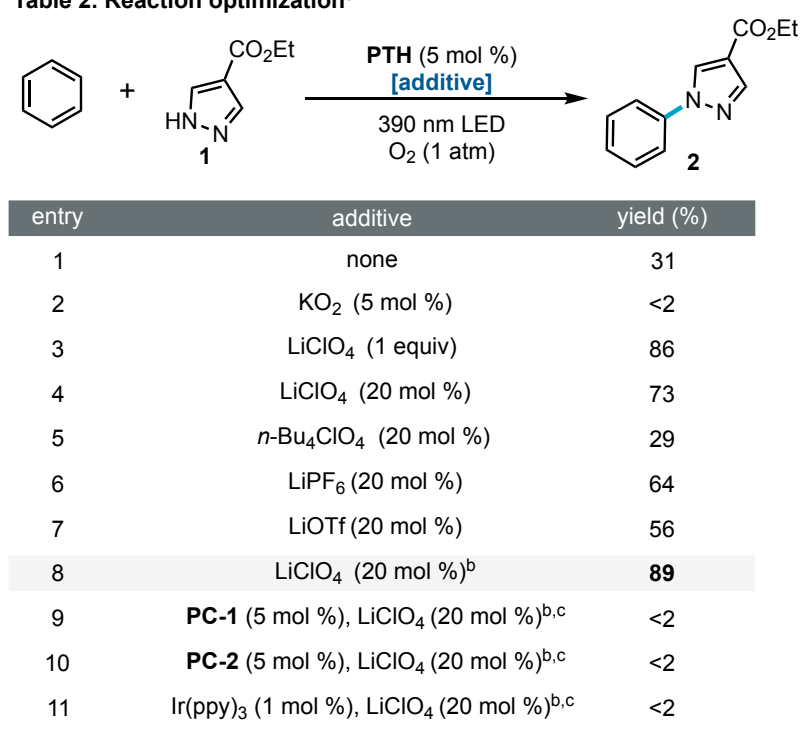

aReactions were conducted on a $0.05 \mathrm{mmol}$ scale in 1:1 TFE:PhH for 24h. See SI for details. ${ }^{b} 9: 1: 10$ TFE:HFIP:PhH solvent mixture. ${ }^{\mathrm{C}}$ Tuna Blue Kessil lamp irradiation. of the additive, suggesting a co-catalytic role for $\mathrm{LiClO}_{4}$ rather than it purely sequestrating stoichiometric byproducts (entry 4). In principle, the lithium co-catalyst could mitigate BET by promoting superoxide disproportionation. ${ }^{29}$ Consistent with this proposed Lewis acidic role, alkylammonium salts had no impact on the reaction (entry 5); whereas, other Lewis acidic lithium salts retained the catalytic effect (entries 6 and 7). Final tuning of the reaction parameters revealed adjusting the solvent mixture to include a small amount of hexafluoroisopropanol (HFIP) delivered the desired product in $89 \%$ yield (entry 8). Substitution of PTH with other triarylamine photoreductants or a classic metal-based photoreductant, $\operatorname{Ir}(\mathrm{ppy})_{3}$, resulted in only trace yield of oxidation product under these otherwise optimal conditions (entries 9-11).

Having identified a promising catalytic system, we examined the scope of this new process (Table 3). Pyrazole nucleophiles bearing a range of electron-withdrawing moieties, including ketones (3), aldehydes (4), nitriles (5), and trifluoromethyl groups (6) were oxidatively coupled to benzene. Halogenated pyrazoles (7 and 8 ) were also productively coupled despite the fact that PTH is a potent photoreductant. Prior approaches capable of oxidizing benzene have not been readily amenable to the arylation of neutral heterocyclic substrates. ${ }^{30}$ In contrast, we observed coupling of both parent pyrazole (9) and even an electronrich analog (10), albeit in diminished yield relative to the electron deficient heterocyclic coupling partners. In addition to pyrazole derivatives, we found that 1,2,3triazoles (11 and 12) were amenable to oxidative coupling

Table 3. Scope of Arene C-H Amination.,

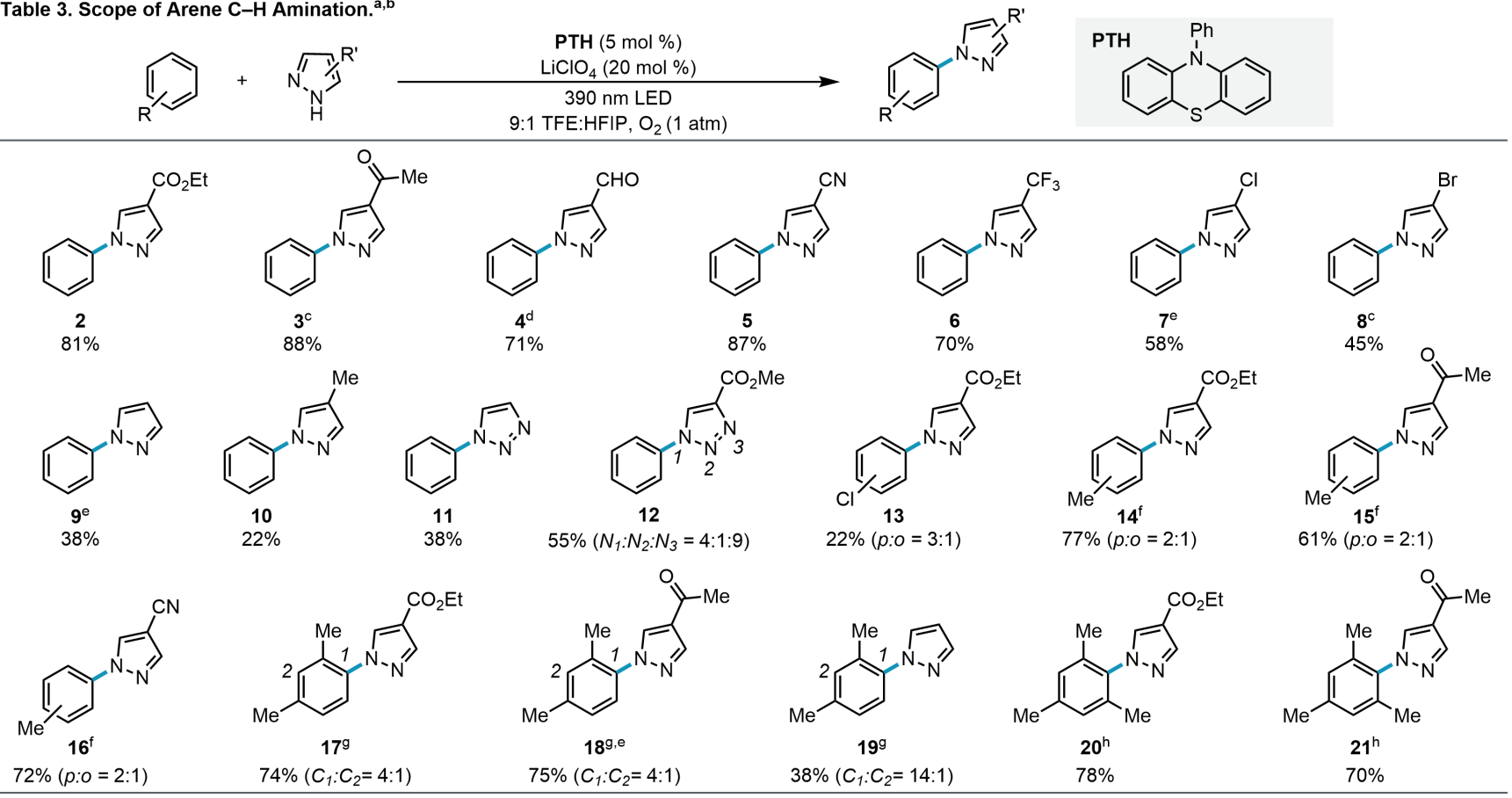

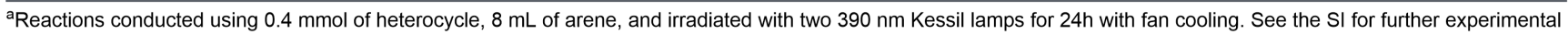
details. ${ }^{b}$ Isolated yields. ${ }^{c} 20 \%$ LiPF $_{6}$. ${ }^{d} 1: 1 \mathrm{HFIP}: \mathrm{PhH}$ solvent. ${ }^{e} \mathrm{NMR}$ yield. ${ }^{\mathrm{f}} 1: 1: 2 \mathrm{MeCN}$ :HFIP:arene solvent with $10 \% t$-dodecyl mercaptan. ${ }^{\mathrm{g}} 10$ equiv arene, $0.1 \mathrm{M}$ in $1: 1$ MeCN:HFIP, $10 \% t$-dodecyl mercaptan. ${ }^{h_{5}}$ equiv arene, $0.1 \mathrm{M}$ in $1: 1 \mathrm{MeCN}: \mathrm{HFIP}, 10 \% t$-dodecyl mercaptan. 
with benzene. Even an exceptionally challenging to oxidize electron-deficient arene, chlorobenzene, could be engaged in productive $\mathrm{C}\left(\mathrm{sp}^{2}\right)-\mathrm{N}$ coupling via arene photooxidation (13). To probe the limits of the system, we evaluated acetophenone as an arene substrate and detected at most traces of oxidative coupling products, indicating that this arene is too electronically deactivated for oxidation under these conditions. We recognized that benzylic $\mathrm{C}-\mathrm{H}$ bonds could be a liability under these aerobic conditions; however, we found reasonable $\mathrm{C}\left(\mathrm{sp}^{2}\right)-\mathrm{N}$ coupling yields could be obtained from toluene using our standard conditions and these yields could be further improved by tuning the reaction conditions to mitigate benzylic oxidation processes. ${ }^{31}$ Under these modified conditions, PTH promoted the photochemical coupling of toluene, $m$ xylene, and mesitylene with pyrazole derivatives in high yield (14-21). The oxidation of $m$-xylene and mesitylene could be achieved using a smaller excess of arene, presumably due to the significantly lower oxidation potential relative to benzene. ${ }^{32}$ Of note, while the scope and reagent stoichiometries required for this approach are similar to prior electrophotocatalytic systems, these simple photocatalytic conditions appear to be more active and deliver coupling products with shorter reaction times. ${ }^{33}$ Overall, these data illustrate that the scope of this photochemical process disclosed herein is on par with complementary electrophotocatalytic approaches. ${ }^{20}$

Next, we aimed to uncover preliminary mechanistic insight into this new and unusually oxidizing photocatalytic system. First, we collected the full reaction profile by monitoring the yield of coupling product $\mathbf{2}$ as a function of time (Scheme 1A). These data revealed an induction period, wherein only a trace amount of product is formed, followed by $0^{\text {th }}$ order formation of product that continues until nearly all of the pyrazole is consumed (see SI for complete reaction profile). If irradiation is temporarily suspended during the induction period, the onset of product formation is correspondingly delayed (Scheme 1B). Similarly, when irradiation is halted during the product-forming regime, the reaction ceases until irradiation resumes (Scheme 1C). Overall, these data are consistent with a mechanism involving an initial photochemical catalyst activation step (e.g. photooxidation of PTH to the radical cation) followed by a productforming regime with either rate-limiting catalyst oxidation or benzene oxidation, given both benzene and $\mathrm{O}_{2}$ are present in excess throughout the reaction. Additionally, we determined the $\mathrm{O}_{2}$ stoichiometry of the reaction by measuring gas consumption within a sealed reaction vessel equipped with a pressure transducer (Figure S16) ${ }^{34}$ These data indicate that just over 2 equivalents of $\mathrm{O}_{2}$ are consumed over the course of the reaction, consistent with $\mathrm{O}_{2}$ acting as only a one-electron oxidant. ${ }^{35}$ As anticipated, we found that only minimal oxygen is consumed during the induction period.
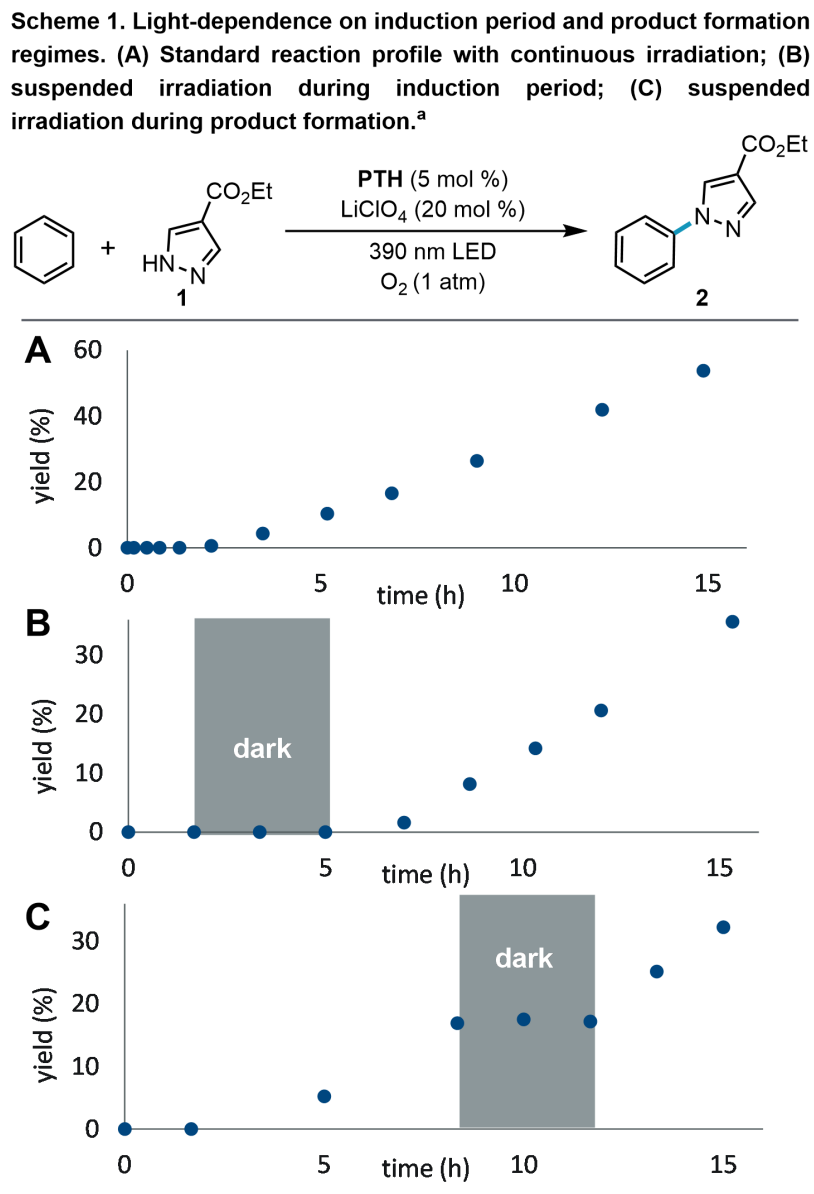

a Reactions were conducted on a $0.05 \mathrm{mmol}$ scale in 9:1:10 TFE:HFIP:PhH. See the Supporting Information (SI) for overlays of total irradation time.

Given the initially unanticipated co-catalytic role of $\mathrm{LiClO}_{4}$ in this system, we next carefully investigated the origin of its impact on the reaction. Omission of this additive resulted in a modest elongation of the induction period and, subsequently, slower product formation (see SI for details). Systematic variation of the concentration of $\mathrm{LiClO}_{4}$ revealed that the impact of this reaction Scheme 2. Saturation in lithium co-catalyst. ${ }^{a}$
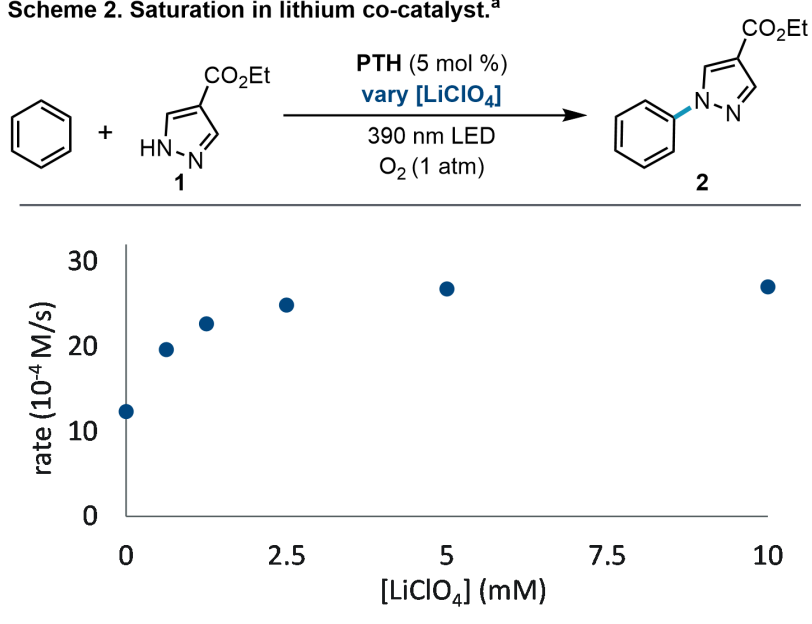

$\overline{{ }^{a} \text { Reactions were conducted on a } 0.05 \mathrm{mmol} \text { scale in 9:1:10 TFE:HFIP:PhH. }}$ 
component on rate saturates at roughly $20 \mathrm{~mol} \%$ (Scheme 2 ). These data are consistent with our working model wherein $\mathrm{LiClO}_{4}$ catalytically scavenges inhibitory reactive oxygen species produced through photochemical $\mathrm{O}_{2}$ reduction. Once the inhibitor is scavenged at a sufficiently rapid rate, its steady state concentration will approach zero and additional increase in co-catalyst loading is expected to have no impact on the process. When the reaction is charged with $5 \mathrm{~mol} \% \mathrm{KO}_{2}$ shortly after the induction period, we observe that the reaction halts thereafter in the absence of $\mathrm{LiClO}_{4}$. In stark contrast, a reaction containing 2 equivalents of $\mathrm{LiClO}_{4}$ was unperturbed by direct addition of this inhibitor (Scheme 3). ${ }^{36}$

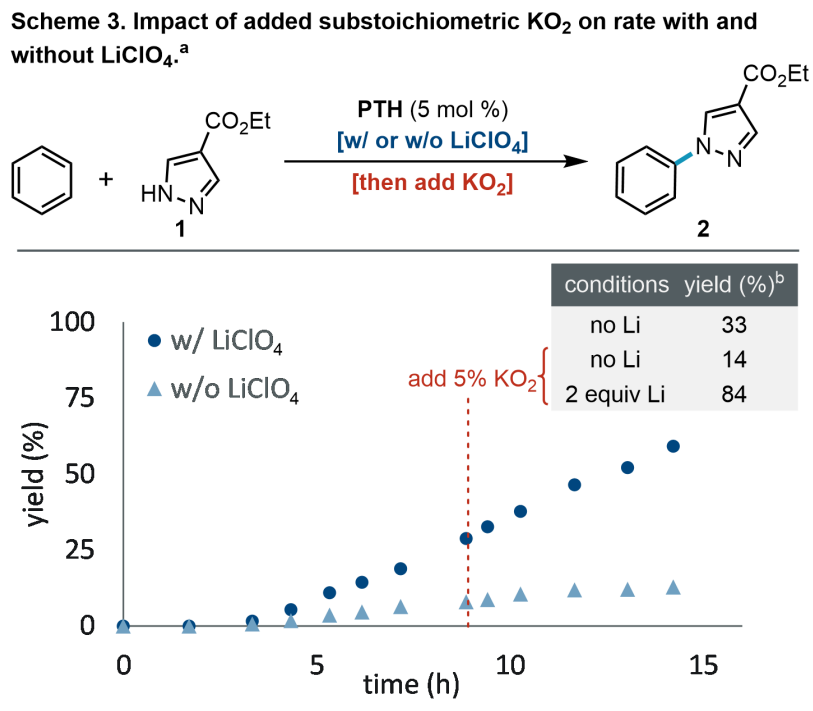

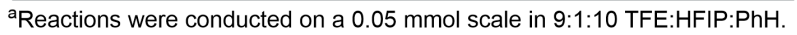
See the Supporting Information (SI) for further details. ${ }^{b}$ final yield after $22 \mathrm{~h}$.

Based on the data presented herein, we have constructed a plausible mechanistic model, which involves: (1) initial oxidative activation of PTH via photoreduction of $\mathrm{O}_{2} ;$ (2) photoexcitation of a triarylamine radical cation to oxidize the arene substrate; $;^{37,38}$ (3) trapping of arene radical cation with pyrazole nucleophile. While lithium salts are not mechanistically necessary to promote the photocatalytic transformation, we suspect that these Lewis acidic cocatalysts accelerate the reaction by promoting the disproportionation of superoxide, an inhibitor inextricably formed in the aerobic catalyst activation step. We envision the lithium co-catalyst is turned over by protonation of $\mathrm{Li}_{2} \mathrm{O}_{2}$ by HFIP. ${ }^{39}$

Overall, we have identified a catalytic system that unlocks potent photooxidant behavior from one of the most reducing conventional photoredox catalysts, PTH. This approach enables oxidative $\mathrm{C}\left(\mathrm{sp}^{2}\right)-\mathrm{N}$ coupling via photooxidation of arene substrates outside of the redox window of reported photoredox approaches. Preliminary mechanistic studies are fully consistent with photocatalyst activation via photoreduction of $\mathrm{O}_{2}$. Intriguingly, we found that Lewis acid co-catalysts could promote and maintain catalyst activation. Beyond providing the first example of purely photochemical benzene oxidation using inexpensive LEDs, this study provides a roadmap to exploit known photocatalysts in new and unconventional ways. We anticipate that continued examination of reaction conditions that force photocatalysts into destabilized oxidation states will dramatically expand the scope of oxidative photoredox catalysis.

\section{AUTHOR INFORMATION}

\section{Corresponding Author}

*wickens@wisc.edu

ORCID

Karina Targos: 0000-0002-9945-0719

Oliver P. Williams: 0000-0002-3897-6426

Zachary K. Wickens: 0000-0002-5733-5288

\section{Author Contributions}

*These authors contributed equally.

Notes

No competing financial interests have been declared.

\section{ACKNOWLEDGMENT}

We thank Prof. Tehshik Yoon and Prof. Alison Wendlandt for helpful suggestions and manuscript proofreading. We thank the Stahl, Weix, Yoon and Schomaker groups for sharing their chemical inventory. We thank Dr. Jack Twilton (Stahl lab) for assistance measuring $\mathrm{O}_{2}$ uptake. This work was financially supported by the Office of the Vice Chancellor for Research and Graduate Education at the University of Wisconsin-Madison with funding from the Wisconsin Alumni Research Foundation. Acknowledgment is made to the Donors of the American Chemical Society Petroleum Research Fund for partial funding of this research (60677-DNI1). This material is based upon work supported by the National Science Foundation Graduate Research Fellowship Program under Grant No. DGE-1747503 (K.T.). Any opinions, findings, and conclusions or recommendations expressed in this material are those of the author(s) and do not necessarily reflect the views of the National Science Foundation. Spectroscopic instrumentation was supported by a generous gift from Paul. J. and Margaret M. Bender, NSF (CHE-1048642), and NIH (S10OD012245 and 1S10OD020022-1).

\section{REFERENCES}

(1) (a) Girard, P.; Namy, J. L.; Kagan, H. B. Divalent Lanthanide Derivatives in Organic Synthesis. 1. Mild Preparation of Samarium Iodide and Ytterbium Iodide and Their Use as Reducing or Coupling Agents. J. Am. Chem. Soc. 1980, 102 (8), 2693-2698. (b) Eberson, L. Electron-Transfer Reactions in Organic Chemistry. In Advances in Physical Organic Chemistry; Gold, V., Bethell, D., Eds.; Academic Press, 1982; Vol. 18, pp 79- 
185. (c) Zhang, N.; Samanta, S. R.; Rosen, B. M.; Percec, V. Single Electron Transfer in Radical Ion and Radical-Mediated Organic, Materials and Polymer Synthesis. Chem. Rev. 2014, 114 (11), 5848-5958. (d) Ashby, E. C. Single-Electron Transfer, a Major Reaction Pathway in Organic Chemistry. An Answer to Recent Criticisms. Acc. Chem. Res. 1988, 21 (11), 414-421.

(2) For selected reviews of visible-light photoredox catalysis, see: (a) Romero, N. A.; Nicewicz, D. A. Organic Photoredox Catalysis. Chem. Rev. 2016, 116 (17), 10075-10166. (b) Prier, C. K.; Rankic, D. A.; MacMillan, D. W. C. Visible Light Photoredox Catalysis with Transition Metal Complexes: Applications in Organic Synthesis. Chem. Rev. 2013, 113 (7), 5322-5363. (c) Shaw, M. H.; Twilton, J.; MacMillan, D. W. C. Photoredox Catalysis in Organic Chemistry. J. Org. Chem. 2016, 81 (16), 6898-6926. (d) Marzo, L.; Pagire, S. K.; Reiser, O.; König, B. Visible-Light Photocatalysis: Does It Make a Difference in Organic Synthesis? Angew. Chem. Int. Ed. 2018, 57 (32), 10034 10072.

(3) Commonly employed photoredox employ wavelengths between $390 \mathrm{~nm}$ and $540 \mathrm{~nm}$ due to the widespread availability of inexpensive and safe LEDs in this range. These wavelengths correspond to a maximum energy of 3.2 and $2.3 \mathrm{eV}$, respectively.

(4) Arias-Rotondo, D. M.; McCusker, J. K. The Photophysics of Photoredox Catalysis: A Roadmap for Catalyst Design. Chem. Soc. Rev. 2016, 45 (21), 5803-5820.

(5) (a) Vega-Peñaloza, A.; Mateos, J.; Companyó, X.; Escudero-Casao, M.; Dell'Amico, L. A Rational Approach to Organo-Photocatalysis: Novel Designs and Structure-Property Relationships. Angew. Chem. Int. Ed. Early View https://doi.org/10.1002/anie.202006416. (b) Speckmeier, E.; Fischer, T. G.; Zeitler, K. A Toolbox Approach To Construct Broadly Applicable Metal-Free Catalysts for Photoredox Chemistry: Deliberate Tuning of Redox Potentials and Importance of Halogens in Donor-Acceptor Cyanoarenes. J. Am. Chem. Soc. 2018, 140 (45), 15353-15365. (c) Sartor, S. M.; McCarthy, B. G.; Pearson, R. M.; Miyake, G. M.; Damrauer, N. $\mathrm{H}$. Exploiting Charge-Transfer States for Maximizing Intersystem Crossing Yields in Organic Photoredox Catalysts. J. Am. Chem. Soc. 2018, 140 (14), 4778-4781. (d) Joshi-Pangu, A.; Lévesque, F.; Roth, H. G.; Oliver, S. F.; Campeau, L.-C.; Nicewicz, D.; DiRocco, D. A. Acridinium-Based Photocatalysts: A Sustainable Option in Photoredox Catalysis. J. Org. Chem. 2016, 81 (16), 7244-7249. (e) Lee, Y.; Kwon, M. S. Emerging Organic Photoredox Catalysts for Organic Transformations. Eur. J. Org. Chem. 2020, 38, 6028-6043 (f) Singh, V. K.; Yu, C.; Badgujar, S.; Kim, Y.; Kwon, Y.; Kim, D.; Lee, J.; Akhter, T.; Thangavel, G.; Park, L. S.; Lee, J.; Nandajan, P. C.; Wannemacher, R.; MiliánMedina, B.; Lüer, L.; Kim, K. S.; Gierschner, J.; Kwon, M. S. Highly Efficient Organic Photocatalysts Discovered via a Computer-Aided-Design Strategy for Visible-Light-Driven Atom Transfer Radical Polymerization. Nat. Catal. 2018, 1 (10), 794804. (g) Glaser, F.; Wenger, O. S. Recent Progress in the Development of Transition-Metal Based Photoredox Catalysts. Coord. Chem. Rev. 2020, 405, 213129.

(6) For an example of UV light promoted oxidation of benzene, see: (a) Ohkubo, K.; Kobayashi, T.; Fukuzumi, S. Direct Oxygenation of Benzene to Phenol Using Quinolinium Ions as Homogeneous Photocatalysts. Angew. Chem. 2011, 123 (37), 8811-8814. For a recent advance in visible light photocatalytic oxidations, see: (b) Pistritto, V. A.; Schutzbach-Horton, M. E.; Nicewicz, D. A. Nucleophilic Aromatic Substitution of Unactivated Fluoroarenes Enabled by Organic Photoredox Catalysis. J. Am. Chem. Soc. 2020, 142 (40), 17187-17194. For two examples of strong photoreductants, see: (c) Matsubara, R.; Yabuta, T.; Md Idros, U.; Hayashi, M.; Ema, F.; Kobori, Y.; Sakata, K. UVA- and Visible-Light-Mediated Generation of Carbon Radicals from Organochlorides Using Nonmetal Photocatalyst. J. Org. Chem.
2018, 83 (16), 9381-9390. (d) Treat, N. J.; Sprafke, H.; Kramer, J. W.; Clark, P. G.; Barton, B. E.; Read de Alaniz, J.; Fors, B. P.; Hawker, C. J. Metal-Free Atom Transfer Radical Polymerization. J. Am. Chem. Soc. 2014, 136 (45), 16096-16101.

(7) For a compilation of potentials of common organic molecules, see: Roth, H.; Romero, N.; Nicewicz, D. Experimental and Calculated Electrochemical Potentials of Common Organic Molecules for Applications to Single-Electron Redox Chemistry. Synlett 2015, 27 (05), 714-723.

(8) For the seminal example of the conPET strategy, see: (a) Ghosh, I.; Ghosh, T.; Bardagi, J. I.; Konig, B. Reduction of Aryl Halides by Consecutive Visible Light-Induced Electron Transfer Processes. Science 2014, 346 (6210), 725-728. For a recent review of work in conPET, see: (b) Glaser, F.; Kerzig, C.; Wenger, O. S. Multi-Photon Excitation in Photoredox Catalysis: Concepts, Applications, Methods. Angew. Chem. Int. Ed. 2020, 59 (26), 10266-10284.

(9) (a) Neumeier, M.; Sampedro, D.; Májek, M.; de la Peña O’Shea, V. A.; Jacobi von Wangelin, A.; Pérez-Ruiz, R. Dichromatic Photocatalytic Substitutions of Aryl Halides with a Small Organic Dye. Chem. - Eur. J. 2018, 24 (1), 105-108. (b) Ghosh, I.; König, B. Chromoselective Photocatalysis: Controlled Bond Activation through Light-Color Regulation of Redox Potentials. Angew. Chem. Int. Ed. 2016, 55 (27), 7676-7679. (c) Bardagi, J. I.; Ghosh, I.; Schmalzbauer, M.; Ghosh, T.; König, B. Anthraquinones as Photoredox Catalysts for the Reductive Activation of Aryl Halides: Anthraquinones as Photoredox Catalysts for the Reductive Activation of Aryl Halides. Eur. J. Org. Chem. 2018, 2018 (1), 34-40. (d) Kerzig, C.; Wenger, O. S. Reactivity Control of a Photocatalytic System by Changing the Light Intensity. Chem. Sci. 2019, 10 (48), 11023-11029. (e) Connell, T. U.; Fraser, C. L.; Czyz, M. L.; Smith, Z. M.; Hayne, D. J.; Doeven, E. H.; Agugiaro, J.; Wilson, D. J. D.; Adcock, J. L.; Scully, A. D.; Gómez, D. E.; Barnett, N. W.; Polyzos, A.; Francis, P. S. The Tandem Photoredox Catalysis Mechanism of $\left[\operatorname{Ir}(p p y)_{2}\right.$ (dtb-bpy) $]^{+}$Enabling Access to Energy Demanding Organic Substrates. J. Am. Chem. Soc. 2019, 141 (44), 17646-17658. (f) Naumann, R.; Lehmann, F.; Goez, M. Micellized Tris(Bipyridine)Ruthenium Catalysts Affording Preparative Amounts of Hydrated Electrons with a Green Light-Emitting Diode. Chem. - Eur. J. 2018, 24 (50), 13259-13269. (g) Qiao, Y.; Yang, Q.; Schelter, E. J. Photoinduced Miyaura Borylation by a Rare-Earth-Metal Photoreductant: The Hexachlorocerate(III) Anion. Angew. Chem. Int. Ed. 2018, 57 (34), 10999-11003. (h) Majek, M.; Faltermeier, U.; Dick, B.; Pérez-Ruiz, R.; Jacobi von Wangelin, A. Application of Visible-to-UV Photon Upconversion to Photoredox Catalysis: The Activation of Aryl Bromides. Chem. - Eur. J. 2015, 21 (44), 15496-15501.

(10) Cole, J. P.; Chen, D.-F.; Kudisch, M.; Pearson, R. M.; Lim, C.-H.; Miyake, G. M. Organocatalyzed Birch Reduction Driven by Visible Light. J. Am. Chem. Soc. 2020, 142 (31), 13573-13581.

(11) MacKenzie, I. A.; Wang, L.; Onuska, N. P. R.; Williams, O. F.; Begam, K.; Moran, A. M.; Dunietz, B. D.; Nicewicz, D. A. Discovery and Characterization of an Acridine Radical Photoreductant. Nature 2020, 580 (7801), 76-80.

(12) While trialkylamines are a commonly employed reductants in both conventional and conPET photoredox processes, the oxidants employed in photoredox catalysis are typically incorporated into the final product and examples of bystanding terminal oxidants in photoredox catalysis are less common.

(13) (a) Margrey, K. A.; Nicewicz, D. A. A General Approach to Catalytic Alkene Anti-Markovnikov Hydrofunctionalization Reactions via Acridinium Photoredox Catalysis. Acc. Chem. Res. 2016, 49 (9), 1997-2006. (b) Prier, C. K.; MacMillan, D. W. C. Amine $\alpha-$ Heteroarylation via Photoredox Catalysis: A Homolytic Aromatic Substitution Pathway. Chem. Sci. 2014, 5 (11), 4173-4178..(c) Terrett, J. A.; Clift, M. D.; MacMillan, D. W. C. Direct $\beta$-Alkylation 
of Aldehydes via Photoredox Organocatalysis. J. Am. Chem. Soc. 2014, 136 (19), 6858-6861. (d) Zuo, Z.; Ahneman, D. T.; Chu, L.; Terrett, J. A.; Doyle, A. G.; MacMillan, D. W. C. Merging Photoredox with Nickel Catalysis: Coupling of $\alpha$-Carboxyl Sp3Carbons with Aryl Halides. Science 2014, 345 (6195), 437-440. (e) Romero, N. A.; Margrey, K. A.; Tay, N. E.; Nicewicz, D. A. SiteSelective Arene C-H Amination via Photoredox Catalysis. Science 2015, 349 (6254), 1326-1330. (f) Niu, L.; Yi, H.; Wang, S.; Liu, T.; Liu, J.; Lei, A. Photo-Induced Oxidant-Free Oxidative $\mathrm{C}-\mathrm{H} / \mathrm{N}-\mathrm{H}$ Cross-Coupling between Arenes and Azoles. Nat. Commun. 2017, 8 (1), 14226

(14) Cowper, N. G. W.; Chernowsky, C. P.; Williams, O. P.; Wickens, Z. K. Potent Reductants via Electron-Primed Photoredox Catalysis: Unlocking Aryl Chlorides for Radical Coupling. J. Am. Chem. Soc. 2020, 142 (5), 2093-2099.

(15) Nicewicz and coworkers recently illustrated that acridinium photooxidants can be transformed into potent photoreductants through photoreduction to the acridine radical. However, it remains unclear whether this inversion of available redox potentials-from strong photooxidant to photoreductant-is a unique feature of acridinium photocatalysts or whether the behavior of other photocatalysts could be similarly manipulated by careful selection of reaction conditions.

(16) Du, Y.; Pearson, R. M.; Lim, C.-H.; Sartor, S. M.; Ryan, M. D.; Yang, H.; Damrauer, N. H.; Miyake, G. M. Strongly Reducing, VisibleLight Organic Photoredox Catalysts as Sustainable Alternatives to Precious Metals. Chem. - Eur. J. 2017, 23 (46), 10962-10968

(17) (a) Christensen, J. A.; Phelan, B. T.; Chaudhuri, S.; Acharya, A.; Batista, V. S.; Wasielewski, M. R. Phenothiazine Radical Cation Excited States as Super-Oxidants for Energy-Demanding Reactions. J. Am. Chem. Soc. 2018, 140 (15), 5290-5299. (b) Rombach, D.; Wagenknecht, H.-A. Photoredox Catalytic Activation of Sulfur Hexafluoride for Pentafluorosulfanylation of $\alpha$-Methyl- and $\alpha$ Phenyl Styrene. ChemCatChem 2018, 10 (14), 2955-2961.

(18) Chan, C.-M.; Chow, Y.-C.; Yu, W.-Y. Recent Advances in Photocatalytic C-N Bond Coupling Reactions. Synthesis 2020, s0040-1707136. https://doi.org/10.1055/s-0040-1707136.

(19) For examples proposing excitation of DDQ to oxidize benzene, see (a) Ohkubo, K.; Fujimoto, A.; Fukuzumi, S. Visible-Light-Induced Oxygenation of Benzene by the Triplet Excited State of 2,3Dichloro-5,6-Dicyano- $p$-Benzoquinone. J. Am. Chem. Soc. 2013, 135 (14), 5368-5371.; (b) Das, S.; Natarajan, P.; König, B. Teaching Old Compounds New Tricks: DDQ-Photocatalyzed $\mathrm{C}-\mathrm{H}$ Amination of Arenes with Carbamates, Urea, and NHeterocycles. Chem. - Eur. J. 2017, 23 (72), 18161-18165.

(20) (a) Huang, H.; Strater, Z. M.; Rauch, M.; Shee, J.; Sisto, T. J.; Nuckolls, C.; Lambert, T. H. Electrophotocatalysis with a Trisaminocyclopropenium Radical Dication. Angew. Chem. Int. Ed. 2019, 58 (38), 13318-13322. (b) Wu, S.; Zurauskas, J.; Domanski, M.; Hitzfeld, P.; Butera, V.; Scott, D.; Rehbein, J.; Kumar, A.; Thyrhaug, E.; Hauer, J.; Barham, J. Hole-Mediated PhotoRedox Catalysis: Tris(p-Substituted)Biarylaminium Radical Cations as Tunable, Precomplexing and Potent Photooxidants. Chem Rxiv, 2020, https://doi.org/10.26434/chemrxiv.13140053.v1.

(21) Photoanodes have also been used to promote the oxidative coupling of pyrazoles and arenes, however, this approach exhibits the same limitations of conventional photoredox catalysts and examples are limited to electron-rich systems, for examples, see: Zhang, L.; Liardet, L.; Luo, J.; Ren, D.; Grätzel, M.; Hu, X. Photoelectrocatalytic Arene C-H Amination. Nat. Catal. 2019, 2 (4), 366-373.

(22) (a) Pearson, R. M.; Lim, C.-H.; McCarthy, B. G.; Musgrave, C. B.; Miyake, G. M. Organocatalyzed Atom Transfer Radical Polymerization Using $N$-Aryl Phenoxazines as Photoredox Catalysts. J. Am. Chem. Soc. 2016, 138 (35), 11399-11407. (b) Theriot, J. C.; Lim, C.-H.; Yang, H.; Ryan, M. D.; Musgrave, C. B.; Miyake, G. M. Organocatalyzed Atom Transfer Radical
Polymerization Driven by Visible Light. Science 2016, 352 (6289), 1082-1086.

(23) Merkel, P. B.; Luo, P.; Dinnocenzo, J. P.; Farid, S. Accurate Oxidation Potentials of Benzene and Biphenyl Derivatives via Electron-Transfer Equilibria and Transient Kinetics. J. Org. Chem. 2009, 74 (15), 5163-5173.

(24) Connelly, N. G.; Geiger, W. E. Chemical Redox Agents for Organometallic Chemistry. Chem. Rev. 1996, 96 (2), 877-910.

(25) (a) Colomer, I.; Chamberlain, A. E. R.; Haughey, M. B.; Donohoe, T. J. Hexafluoroisopropanol as a Highly Versatile Solvent. Nat. Rev. Chem. 2017, 1 (11), 1-12. (b) Shida, N.; Imada, Y.; Nagahara, S.; Okada, Y.; Chiba, K. Interplay of Arene Radical Cations with Anions and Fluorinated Alcohols in Hole Catalysis. Commun. Chem. 2019, 2 (1), 1-8. (c) Eberson, L.; Hartshorn, M. P.; Persson, O.; Radner, F. Making Radical Cations Live Longer. Chem. Commun. 1996, No. 18, 2105.

(26) Discekici, E. H.; Treat, N. J.; Poelma, S. O.; Mattson, K. M.; Hudson, Z. M.; Luo, Y.; Hawker, C. J.; de Alaniz, J. R. A Highly Reducing Metal-Free Photoredox Catalyst: Design and Application in Radical Dehalogenations. Chem. Commun. 2015, 51 (58), 11705-11708.

(27) Based on our working model, superoxide would be formed after $\mathrm{O}_{2}$ reduction. Other reduced oxygen species could also act as inhibitors for the reaction through either BET or another mechanism.

(28) For redox potentials of various reactive oxygen species, see: Krumova, K.; Cosa, G.; Chapter 1. Overview of Reactive Oxygen Species. 1-21.

(29) (a) Lu, Y.-C.; Gallant, B. M.; Kwabi, D. G.; Harding, J. R.; Mitchell, R. R.; Whittingham, M. S.; Shao-Horn, Y. Lithium-Oxygen Batteries: Bridging Mechanistic Understanding and Battery Performance. Energy Environ. Sci. 2013, 6 (3), 750. (b) Sawyer, D. T.; Chiericato, Glaico.; Angelis, C. T.; Nanni, E. J.; Tsuchiya, Tohru. Effects of Media and Electrode Materials on the Electrochemical Reduction of Dioxygen. Anal. Chem. 1982, 54 (11), 1720-1724.

(30) For an example of photochemical coupling of benzene and pyrazole coupling in $22 \%$ yield, see: Ref. $19 \mathrm{~b}$

(31) We found that blending $\mathrm{MeCN}$ back into the solvent mixture reduced the activity of the system. This change improved the yields for these easier to oxidize substrates. Additionally, $t$-dodecyl mercaptan was employed as a co-catalyst in place of $\mathrm{Li}$, we suspect this co-catalyst could either function similarly by hydrogen atom transfer to superoxide or through alternative an mechanism. See SI for details.

(32) While benzene possesses an oxidation potential of $2.5 \mathrm{~V} v \mathrm{~s}$. SCE, $m$ xylene and mesitylene possess oxidation potentials of 2.05 and 2.1 vs. SCE respectively. For further information, see ref. 23.

(33) Typical reaction times were $48-72 \mathrm{~h}$ in the electrophotocatalytic approaches reported in ref. 20a and $b$.

(34) For a recent example using the gas uptake apparatus employed herein, see: Ryan, M. C.; Kim, Y. J.; Gerken, J. B.; Wang, F.; Aristov, M. M.; Martinelli, J. R.; Stahl, S. S. Mechanistic Insights into Copper-Catalyzed Aerobic Oxidative Coupling of N-N Bonds. Chem. Sci. 2020, 11 (4), 1170-1175.

(35) In principle, $\mathrm{O}_{2}$ can accept between one and four electrons in oxidative processes, see: Stahl, S. S. Palladium Oxidase Catalysis: Selective Oxidation of Organic Chemicals by Direct DioxygenCoupled Turnover. Angew. Chem. Int. Ed. 2004, 43 (26), 34003420.

(36) Adding $\mathrm{LiClO}_{4}$ could also recover a reaction inhibited by $\mathrm{KO}_{2}(5$ mol \%) addition. See SI for details.

(37) While the expected excited state lifetime of the PTH radical cation is $<1 \mathrm{~ns}$ and likely too short for intermolecular photocatalysis requiring diffusion (based on Ref. 17a), we suspect that preassociation between the catalyst and the arene may be responsible for photochemical activity. Studies are ongoing into the nature of the active catalytic photooxidant. 
(38) Catalyst decomposition to an active photocatalyst has been suggested as a mechanistic revision in other conPET systems and cannot be excluded here. For an example, see: Marchini, M.; Gualandi, A.; Mengozzi, L.; Franchi, P.; Lucarini, M.; Cozzi, P. G.; Balzani, V.; Ceroni, P. Mechanistic Insights into Two-PhotonDriven Photocatalysis in Organic Synthesis. Phys. Chem. Chem. Phys. 2018, 20 (12), 8071-8076.

(39) The $\mathrm{p} K_{\mathrm{a}}$ of HFIP is 9.3 and the $\mathrm{p} K_{\mathrm{a}}$ of $\mathrm{H}_{2} \mathrm{O}_{2}$ is 11.6. 